\title{
Degradation of chlorinated butenes and butadienes by granular iron
}

\author{
R. E. Hughes, R. W. Gillham \& L. Gui \\ Department of Earth and Environmental Sciences, \\ University of Waterloo, Canada
}

\begin{abstract}
Sites where chlorobutyl rubber is produced have the potential to release a mixture of chlorinated butenes and butadienes, which are known to be toxic and persistent, into the groundwater environment. The potential contaminants include trans-1,4-dichlorobutene-2 (1,4-DCB-2), 3,4-dichlorobutene-1 (3,4-DCB-1), 2,3,4-trichlorobutene-1 (2,3,4-TCB-1), 2-chlorobutadiene-1,3 (chloroprene) and 2,3-dichlorobutadiene-1,3 (DCBD). Granular iron has been shown to reductively dechlorinate a number of compounds and has been used in permeable reactive barriers (PRBs) for in-situ groundwater remediation. To evaluate the possibility of using granular iron for the remediation of the above contaminants, a series of batch experiments were conducted. Results show that dechlorination reactions for chlorinated butenes closely followed pseudo-first-order kinetics with normalized half-lives ranging from 5.1 to $7.5 \mathrm{~h}$. Chlorinated butadienes degraded much slower in batch tests with normalized half-lives ranging from 38.8 to $128 \mathrm{~h}$. Chlorine mass balance calculations showed that 1,4-DCB-2, 3,4-DCB-1 and chloroprene were fully dechlorinated by granular iron. 2,3,4-TCB-1 was transformed to chloroprene as an intermediate via a reductive $\beta$-elimination pathway. Neither the presence of $\mathrm{CaCO}_{3}$ nor temperature affected degradation rates suggesting that mass transport to iron surfaces was limiting degradation in batch tests. A column experiment was conducted on 3,4-DCB-1 and a normalized half-life of 1.6 min was found. Faster degradation in the column was thought to be due to enhanced mixing effects. 3,4-DCB-1 was converted to 1,3butadiene via reductive $\beta$-elimination, which was then converted to a mixture of 1-butene, cis-2-butene and trans-2-butene via catalytic hydrogenation.
\end{abstract}

Keywords: chlorinated contaminants, granular iron, groundwater remediation, degradation pathways, chlorobutyl contamination. 


\section{Introduction}

A mixture of chlorinated aliphatics including 1,4-dichlorobutene-2 (1,4-DCB-2), 3,4-dichlorobutene-1 (3,4-DCB-1), 2,3,4-trichlorobutene-1 (2,3,4-TCB-1), 2 chlorobutadiene (chloroprene) and 2,3-dichlorobutadiene (DCBD) arise from the synthesis of the chloroprene and DCBD monomers, which are used in the manufacture of chlorobutyl rubber and a number of other materials. Chloroprene production in 1989 reached 373000 tonnes [1]. The reaction processes involved in chloroprene and DCBD synthesis take place in "closed" systems, which are designed to avoid exposure to humans and the environment, but some leaks and accidental spills inevitably occur [2]. These compounds frequently occur in waste streams and have the potential to be released to the subsurface. All of the compounds, with the exception of chloroprene, can be classified as dense nonaqueous phase liquids (DNAPLs) which can penetrate deep below the water table and can result in the generation of large-scale, long-term plumes that are difficult to remediate by conventional methods such as pump-and-treat remediation [3]. Solubilities of these compounds range from 256 to $7190 \mathrm{mg} / \mathrm{L}$ [1, 4-6], suggesting dissolution behaviour is similar to common problematic DNAPL compounds such as trichloroethene (TCE) and tetrachloroethene (PCE). There are no maximum contamination limits (MCLs) for the five chlorinated aliphatics above, however each of the compounds is considered to be toxic [1, 4-8]. Furthermore, 1,4-DCB-2, 3,4-DCB-1 and chloroprene were found to be mutagenic by plate incorporation assay [9] and 1,4-DCB-2, 2,3,4-TCB-1 and chloroprene are considered carcinogenic [1, 10, 11] while 3,4-DCB-1 is considered a potential carcinogen [5]. Thus their release into the environment could have detrimental effects on human and ecological health and their presence in the subsurface may justify remediation efforts.

The use of granular iron has been shown to be an effective treatment in the remediation of other chlorinated aliphatics by reductive dechlorination $[12,13]$. The main objective of this study is therefore to determine if groundwater contaminated with chlorinated butenes and butadienes can also be effectively treated by granular iron. Secondly, the kinetic rates at which the compounds and intermediates degrade have been investigated as they are important in the design of a potential remediation scheme, which could include a permeable reactive barrier (PRB) as described in O'Hannesin and Gillham [14]. The implementation of a remediation scheme will also depend on the toxicity of the end products of degradation and these end products have been monitored for 3,4-DCB-1. The pathways by which dechlorination of organic compounds occurs depends on molecular structure. One such pathway is reductive $\beta$-elimination [13] in which two chlorine atoms on adjacent carbons $(\alpha, \beta$ pair) are removed resulting in a unit increase in bond order between the two carbons. Unsaturated bonds in an organic compound can also be reduced via interaction with granular iron through a process known as catalytic hydrogenation $[13,15]$ in which iron acts as a catalyst in the addition of hydrogen to a double or triple bond. Reactive pathways have been proposed where possible. 


\section{Experimental}

\subsection{Materials}

Granular iron was obtained from Connelly-GMP Inc. Surface area analysis, performed using the $\mathrm{N}_{2}$ BET method with a Micromeritics Gemini III 2372 surface area analyzer, gave an average surface area of $1.33 \mathrm{~m}^{2} / \mathrm{g}$. The compounds 1,4-DCB-2, 2,3,4-TCB-1 and DCBD were obtained from Sirem Laboratories. DCBD was received as a 1:1 mixture $(\mathrm{w} / \mathrm{w})$ with PCE while $1,4-\mathrm{DCB}-2$ and 2,3,4-TCB-1 were received as pure compounds (purity not specified). 3,4-DCB-1 was obtained from Sigma Aldrich (98\%). Standards for these compounds were prepared in methanol. Chloroprene was obtained from Supelco as a $2000 \mathrm{mg} / \mathrm{L}$ standard in methanol. A gaseous mixture of 1,3-butadiene, n-butane, 1-butene, cis-2-butene, ethyl acetylene, isobutene, isobutylene and trans-2-butene (15.4 ppm for each compound, balance nitrogen) was obtained from Scott Specialty Gases and used to create standards for non-chlorinated intermediates and end products. Gaseous concentrations were converted to aqueous concentrations using Henry's Law constants, calculated using the procedure outlined in Schwarzenbach et al [16], and a 1:1 headspace-to-aqueous solution ratio.

\subsection{Batch procedures}

Batch experiments were performed in glass vials (average volume of $37.24 \pm$ $0.42 \mathrm{ml}$ for 1,4-DCB-2, 3,4-DCB-1 and 2,3,4-TCB-1; $14.01 \pm 0.30 \mathrm{ml}$ for chloroprene and DCBD). Each experiment consisted of 8 to 12 sets of 4 vials. Each set consisted of a control vial (contaminant solution only), a chloride control vial (iron with uncontaminated water), and duplicate reaction vials (iron with contaminant solution). Reaction and chloride control vials for experiments on 1,4-DCB-2, 3,4-DCB-1 and 2,3,4-TCB-1 contained $10.01 \pm 0.01 \mathrm{~g}$ of iron while chloroprene and DCBD experiments contained $3.51 \pm 0.02 \mathrm{~g}$ of iron. The contaminant solutions were prepared with either deionized (DI) water or 40 $\mathrm{mg} / \mathrm{L}$ calcium carbonate $\left(\mathrm{CaCO}_{3}\right)$ in DI water, referred to as simulated groundwater or GW. After adjusting the $\mathrm{pH}$ to between 6 and 7, the solutions were spiked with the stock solution of contaminant, stirred for $15 \mathrm{~min}$ and used to fill the contaminant control and reaction vials leaving no headspace. The chloride controls were filled with solution before spiking. The vials were then capped with crimp-top caps and Teflon ${ }^{\circledR}$ lined septa. The iron surface area-tosolution volume ratio was $0.357 \pm 0.004 \mathrm{~m}^{2} / \mathrm{ml}$ for the $1,4-\mathrm{DCB}-2,3,4-\mathrm{DCB}-1$ and 2,3,4-TCB-1 experiments and $0.340 \pm 0.008 \mathrm{~m}^{2} / \mathrm{ml}$ for the chloroprene and DCBD experiments. Batch tests were performed at two temperatures: $10^{\circ} \mathrm{C}$ and $25^{\circ} \mathrm{C}$. All vials were mixed by gently inverting three times by hand at least twice daily. Constant rotary mixing was not used because many experiments were conducted in the refrigerator where that option was unavailable. The chloride control vials were necessary because some chloride was found to be leaching from fresh iron surfaces. At each sampling time, a set of vials was sacrificed for analysis. 


\subsection{Column procedures}

A column experiment was conducted using 3,4-DCB-1 to confirm batch experiment results and to mimic flow through a PRB. The setup for the column experiments is similar to that described in Gillham and O'Hannesin [12]. The column used was made of clear Plexiglas ${ }^{\circledR}$ tubing $30.0 \mathrm{~cm}$ long x $2.50 \mathrm{~cm}$ I.D. The column was packed with $30 \%$ Connelly iron and $70 \%$ Ottawa silica sand $(\mathrm{w} / \mathrm{w})$, which was acid washed with $10 \%$ nitric acid and rinsed until the rinse water reached a $\mathrm{pH}$ of 6.5 . The porosity and pore volume of the column were measured to be 0.39 and $57.2 \mathrm{ml}$, respectively. The iron surface area-to-solution volume ratio was $2.16 \mathrm{~m}^{2} / \mathrm{ml}$. The column was purged for 30 minutes with $\mathrm{CO}_{2}$ gas before it was flushed with a total of 14 pore volumes of DI water for a period of 24 hours. The column experiment was performed at $25^{\circ} \mathrm{C}$. A source solution $\left(9.6 \pm 0.9 \mathrm{mg} / \mathrm{L} 3,4-\mathrm{DCB}-1\right.$ in DI water), contained in a clean Teflon ${ }^{\circledR}$ bag, was introduced using a peristaltic pump from the bottom end of the column. A total of 317 pore volumes were passed through the column at a pore velocity of $7.6 \mathrm{x}$ $10^{-3} \mathrm{~cm} / \mathrm{s}$. A total of 8 sampling events were performed to ensure the chemical profiles of the parent compound, intermediates and end products had reached steady-state (consistent relative concentrations at each sampling port). Samples were obtained from selected sampling ports by removing the plugs and attaching a glass syringe to the needle while the effluent end of the column was clamped. The solution was allowed to flow freely into the syringe as to not change the residence time of the sample being collected. Samples were also taken from the influent and effluent ends of the column.

\subsection{Analytical methods}

Aqueous samples of 1,4-DCB-2, 3,4-DCB-1, 2,3,4-TCB-1, chloroprene and DCBD from batch tests were diluted with Milli-Q water and placed in a $10 \mathrm{ml}$ crimp-top GC vial, leaving $6 \mathrm{ml}$ of headspace. The samples were placed on a rotary shaker for 15 min to allow the aqueous and gas phases to equilibrate then placed on a Hewlett Packard 7694 Headspace autosampler. Headspace samples, $1 \mathrm{ml}$ in volume, were injected into a Hewlett Packard 5890 series II gas chromatograph (GC) with a Ni ${ }^{63}$ electron capture detector (ECD) and a DB-624 capillary column $(30 \mathrm{~m} \times 0.533 \mathrm{~mm})$. The oven temperature program started with an initial temperature of $40^{\circ} \mathrm{C}$, held for $2.0 \mathrm{~min}$, ramped up to $100^{\circ} \mathrm{C}$ at a rate of $10^{\circ} \mathrm{C} / \mathrm{min}$ and held for $10.0 \mathrm{~min}$. The detector temperature was held at $300^{\circ} \mathrm{C}$ and the injector temperature was held at $200^{\circ} \mathrm{C}$. The carrier gas was helium and had a constant flow rate of $7.0 \mathrm{ml} / \mathrm{min}$. The make up gas was $5 \%$ methane and $95 \%$ argon. Method detection limits (MDLs) were 5.0, 4.5, 1.5, 9.6 and $1.0 \mu \mathrm{g} / \mathrm{L}$ for 1,4-DCB-2, 3,4-DCB-1, 2,3,4-TCB-1, chloroprene and DCBD, respectively.

Because DCBD was received as a 1:1 (wt/wt) mixture with PCE, concentrations for PCE and TCE (a breakdown product of PCE) in the batch experiments were also measured using a pentane extraction method followed by GC-ECD analysis, as outlined in Orth and Gillham [17]. MDLs were 5.0, 4.5, and $1.0 \mu \mathrm{g} / \mathrm{L}$ for DCBD, PCE and TCE respectively. 
Chloride ion concentrations in batch and column experiments were analysed so that chlorine mass balances could be calculated. Analysis was done using a Dionex ISC-2000 ion chromatograph equipped with an IonPac AS18 column (4 x 250mm). The MDL was $10 \mu \mathrm{g} / \mathrm{L}$.

Non-chlorinated intermediates and end products were identified and analysed for the column experiment. Samples, $2.5 \mathrm{ml}$ in volume, were put into $5.0 \mathrm{ml}$ vials with Teflon ${ }^{\circledR}$ septa and screw caps, leaving $2.5 \mathrm{ml}$ of headspace. The vials were placed on a rotary shaker for $15 \mathrm{~min}$ to allow the aqueous and gas phases to equilibrate. Headspace samples, $250 \mu \mathrm{l}$ in volume, were then injected manually into a Hewlett Packard 5790 GC with a flame ionization detector (FID) and a GS-Q plot capillary column $(30 \mathrm{~m} \times 0.53 \mathrm{~mm})$. The oven temperature program started with an initial temperature of $90^{\circ} \mathrm{C}$, held for $5.0 \mathrm{~min}$, ramped up at a rate of $15^{\circ} \mathrm{C} / \mathrm{min}$ to a final temperature of $120^{\circ} \mathrm{C}$ and held for $5.0 \mathrm{~min}$. MDLs were $52,49,48,96$ and $51 \mu \mathrm{g} / \mathrm{L}$ for 1,3-butadiene, 1-butene, cis-2-butene, trans-2butene and n-butane respectively.

\section{Results and discussion}

\subsection{Batch experiments}

Table 1 shows the initial conditions and results for each of the compounds in the batch experiments. The three chlorinated butenes, 1,4-DCB-2, 3,4-DCB-1 and 2,3,4-TCB-1, degraded to below detection limits within $150 \mathrm{~h}$ (Figure 1a, b, c) and closely followed the pseudo-first-order kinetic model with half-lives (normalized to an iron surface area-to-solution ratio of $1 \mathrm{~m}^{2} / \mathrm{ml}$ ) ranging from 4.0 to $7.7 \mathrm{~h}$. The two chlorinated butadienes, chloroprene and DCBD, did not degrade to below detection limits within the duration of the experiments. Chloroprene showed $47.5 \%$ and $56 \%$ disappearance for experiments in DI water at $10^{\circ} \mathrm{C}$ and $\mathrm{GW}$ at $25^{\circ} \mathrm{C}$ respectively while DCBD showed $80.9 \%$ and $87.0 \%$ disappearance in DI water at $10^{\circ} \mathrm{C}$ and $\mathrm{GW}$ at $25^{\circ} \mathrm{C}$ respectively. Neither chloroprene nor DCBD showed an initially good fit to the pseudo-first-order kinetic model. The shapes of the degradation curves (Figure 1e, f) show a sharp decline in concentration at early time then a "levelling off" of concentration at later time. This trend is commonly seen in sorption curves and suggests that sorption of the contaminant to the iron surface is at least partially responsible for concentration decline at early time. In the case where sorption is thought to be occurring at early time, one may consider only using later data points to determine degradation kinetics. In the case of chloroprene, however, the fit to the pseudo-first-order kinetic model did not improve when only considering later data and normalized half-lives $\left(128 \mathrm{~h}\right.$ and $79.2 \mathrm{~h}$ for reaction in DI water at $10^{\circ} \mathrm{C}$ and $\mathrm{GW}$ at $25^{\circ} \mathrm{C}$, respectively) are therefore thought to be inaccurate. A good fit $\left(\mathrm{R}^{2}=0.94\right)$ to the pseudo-first-order model was achieved for DCBD when considering data taken after $24 \mathrm{~h}$ giving normalized half-lives of $63.5 \mathrm{~h}$ and 38.8 $\mathrm{h}$ for reaction in DI water at $10^{\circ} \mathrm{C}$ and $\mathrm{GW}$ at $25^{\circ} \mathrm{C}$, respectively.

Chlorine mass balances were thought to contain a great deal of error due to chloride leaching from the iron materials. Calculations for chlorine mass balance, 
however, suggest that 1,4-DCB-2 and 3,4-DCB-1 were fully dechlorinated since no chlorinated intermediates were observed (figure $1 \mathrm{a}, \mathrm{b}$ ). One chlorinated intermediate was observed for reaction of 2,3,4-TCB-1 with iron (Figure 1d) and was identified as chloroprene. The conversion of 2,3,4-TCB-1 to chloroprene is proposed to occur through reductive $\beta$-elimination. Mass balances for chlorine (Figure 1c, Table 1) and carbon (ranged from 59\% to $70 \%$, based on 2,3,4-TCB1 and chloroprene concentrations) were low and may be explained by an unidentified hydrolysis product, believed to be chlorinated, observed in both the control and reaction vials that was unaccounted for. Since chloroprene is a monochlorinated compound, the observation of elevated chloride levels in the reaction vials provides evidence of complete dechlorination of the compound by granular iron. Chlorine mass balances for DCBD were especially low $(16 \%$ $19 \%)$. For these experiments PCE was a co-contaminant in solution $(1: 1 \mathrm{w} / \mathrm{w})$. Sorption of DCBD and/or PCE to iron surfaces likely contributed to the low chlorine mass balances.

Both the presence of calcium carbonate [18] and increases in temperature [19] have been shown to enhance degradation rates. In our study neither of these factors seemed to significantly affect dechlorination rates. This seems to suggest that mass transport to the iron surfaces was the limiting factor for degradation rates in these batch tests since only periodic mixing was used. Preliminary tests

Table 1: $\quad$ Summary of batch experiment initial conditions and results.

\begin{tabular}{|c|c|c|c|c|c|c|}
\hline Contaminant & $\begin{array}{c}\text { DI or } \\
\text { GW }\end{array}$ & $\begin{array}{c}\text { Temp. } \\
\left({ }^{\circ} \mathrm{C}\right)\end{array}$ & $\begin{array}{l}\text { Starting } \\
\text { Conc. } \\
(\mathrm{mg} / \mathrm{L})\end{array}$ & $\begin{array}{c}\text { Norm. Pseudo- } \\
\text { first-order } \\
\text { half-life (h)* }\end{array}$ & $\begin{array}{c}\text { Correlation } \\
\text { Coefficient } \\
\left(\mathbf{R}^{2}\right)\end{array}$ & $\begin{array}{c}\text { Final } \\
\text { Cl mass } \\
\text { bal.(\%) }\end{array}$ \\
\hline \multirow[t]{2}{*}{ 1,4-DCB-2 } & DI & 10 & 11.5 & 7.7 & 0.98 & 93 \\
\hline & GW & 10 & 13.9 & 7.3 & 0.98 & 79 \\
\hline \multirow[t]{3}{*}{ 3,4-DCB-1 } & DI & 10 & 9.6 & 4.0 & 1.00 & 84 \\
\hline & GW & 10 & 9.3 & 5.3 & 0.99 & 101 \\
\hline & DI & 25 & 8.3 & 6.1 & 0.98 & 124 \\
\hline \multirow[t]{3}{*}{ 2,3,4-TCB-1 } & DI & 10 & 9.2 & 5.9 & 0.92 & 79 \\
\hline & GW & 10 & 8.8 & 5.9 & 0.99 & 87 \\
\hline & GW & 25 & 8.7 & 5.8 & 0.98 & 59 \\
\hline \multirow[t]{2}{*}{ Chloroprene } & DI & 10 & 11.2 & 128 & 0.66 & 52 \\
\hline & GW & 25 & 8.5 & 79.2 & 0.67 & 102 \\
\hline \multirow[t]{2}{*}{ DCBD } & DI & 10 & 5.5 & $63.5 * *$ & $0.94 * *$ & 16 \\
\hline & GW & 25 & 2.8 & $38.8^{* *}$ & $0.94 * *$ & 19 \\
\hline
\end{tabular}

* Normalized to an iron surface area-to-solution ratio of $1 \mathrm{~m}^{2} / \mathrm{ml}$.

**Used data points after 24 h only. 

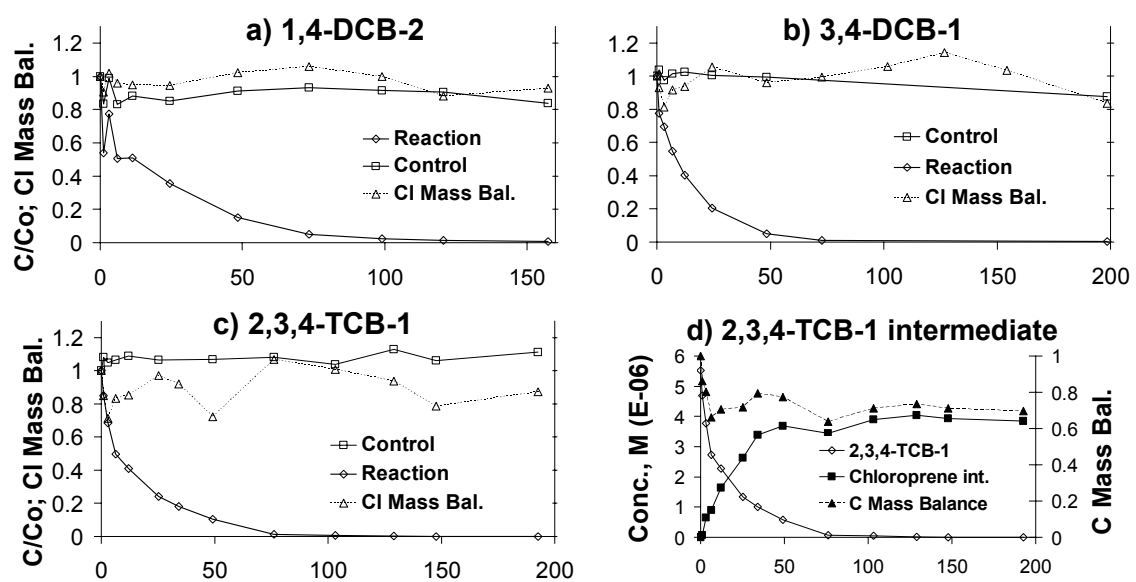

d) 2,3,4-TCB-1 intermediate
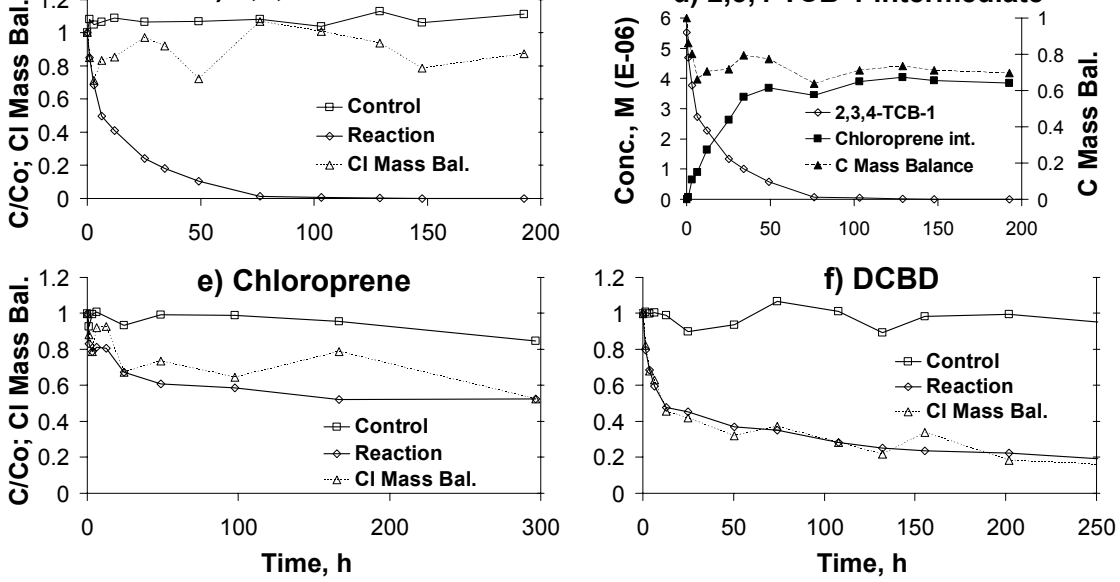

Figure 1: Degradation profiles (reaction), controls and chlorine mass balances for a) 1,4 -DCB-2 in DI water at $10^{\circ} \mathrm{C}$, b) $3,4-\mathrm{DCB}-1$ in DI water at $10^{\circ} \mathrm{C}$, c) $2,3,4-\mathrm{TCB}-1$ in $\mathrm{GW}$ at $10^{\circ} \mathrm{C}$, e) chloroprene in DI water at $10^{\circ} \mathrm{C}$ and $\mathrm{f}$ ) DCBD in DI water at $10^{\circ} \mathrm{C}$. d) Shows the generation of the chloroprene intermediate observed as 2,3,4TCB-1 degrades and the carbon mass balance based on those two compounds.

using 1,4-DCB-2 showed that the compound was disappearing via hydrolysis at $25^{\circ} \mathrm{C}$ with a half-life of $59.8 \mathrm{~h}$. At $10^{\circ} \mathrm{C}$, however, the hydrolysis half-life was much greater $(1155 \mathrm{~h})$ such that disappearance of the compound in batch tests due to hydrolysis was found to be negligible. Batch results for 1,4-DCB-2 at $25^{\circ} \mathrm{C}$ are therefore not included in Table 1 . Hydrolysis was not found to be a major contributor for disappearance of any of the other contaminants at either $25^{\circ} \mathrm{C}$ or $10^{\circ} \mathrm{C}$.

\subsection{Column experiment}

A column experiment was conducted using 3,4-DCB-1. Figure 2 shows the column profiles for all observed organic compounds as well as chlorine and carbon mass balances. Contaminant concentration decreased exponentially to 


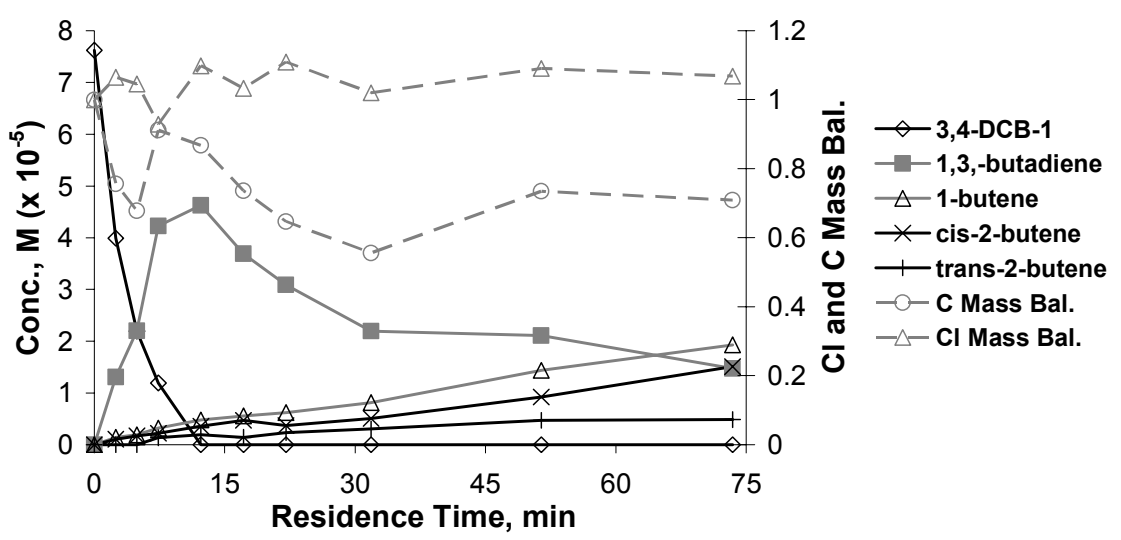

Figure 2: $\quad$ Steady-state column profiles for 3,4-DCB-1 degradation including intermediates, end products, chlorine and carbon mass balances and chlorine mass balance at 317 pore volumes.

below the detection limit within 10 min giving a normalized half-life of $1.6 \mathrm{~min}$ $\left(\mathrm{R}^{2}=0.95\right)$. This value is two orders of magnitude shorter than the average normalized half-life of $5.1 \mathrm{~h}(308 \mathrm{~min})$ for the batch experiments, providing further evidence that mass transport to the iron surfaces may be the limiting factor in determining half-lives in the batch tests. The chlorine mass balance (ranging from $93 \%$ to $110 \%$ ) confirms that 3,4-DCB-1 was fully dechlorinated by granular iron. From Figure 2, it appears that 3,4-DCB-1 was converted initially to 1,3-butadiene. Since no chlorinated intermediates were observed, this likely occurred via reductive $\beta$-elimination. 1,3-butadiene then appeared to degrade with a normalized pseudo-first-order half-life of $89.2 \mathrm{~min}\left(\mathrm{R}^{2}=0.89\right.$, estimated using data points from peak concentration onward) to a mixture of 1butene, cis-2-butene and trans-2-butene. This transformation likely occurred via catalytic hydrogenation consistent with Consorti et al [15] where butadiene underwent hydrogenation catalyzed by transition metal complexes resulting in a mixture of 1-butene, cis-2-butene, trans-2-butene and n-butane. N-butane was not observed in this column experiment, however it is unknown if further catalytic hydrogenation would have occurred if residence times had been greater. Of the observed intermediates and end products, only 1,3-butadiene, a transient intermediate, is considered to be of environmental concern [20]. The carbon mass balance was low ( $71 \%$ at the last sampling port), however some losses were expected to occur during sampling and transfer of solutions as 1,3butadiene, 1-butene, cis-2-butene and trans-2-butene all exist as gases at room temperature and are expected to partition into the gas phase. Both cis-2-butene and trans-2-butene are known to undergo hydrolysis [21], which may also explain some loss of mass for these compounds since analysis for alcohols was not performed. 


\section{Conclusions}

The results of this study show great potential for granular iron as a means for remediation of chlorinated butenes and butadienes in groundwater. Complete dechlorination of 1,4-DCB-2, 3,4-DCB-1 and chloroprene by granular iron has been demonstrated. The major pathway for 2,3,4-TCB-1 degradation was reductive $\beta$-elimination to chloroprene implying that this contaminant can also be dechlorinated. Normalized half-lives showed that chlorinated butenes degraded faster than the chlorinated butadienes. A column experiment using 3,4DCB-1 indicated that improved mixing may increase reaction rates and further column experiments on all compounds are being conducted to better simulate flow through a PRB. This is also expected to minimize the effects of sorption on degradation curves that were seen in the chloroprene and DCBD batch experiments. Reactive pathways for 3,4-DCB-1 were determined and end products were found to be non-harmful. Ongoing work is being conducted to investigate the reactive pathways and end products of the other four contaminants.

\section{References}

[1] International Programme on Chemical Safety (IPCS). OECD screening information data set (SIDS). Chloroprene. UNEP Publications. www.inchem.org/documents/sids/sids/Chloroprene.pdf

[2] Lynch, M., Manufacture and use of chloroprene monomer. ChemicoBiological Interactions, 135-136, pp. 155-167, 2001.

[3] Makay, D.M. \& Cherry, J.A., Groundwater contamination: pump and treat remediation. Environmental Science \& Technology, 23(6), pp. 630-636, 1989.

[4] Blaha, L., Damborski, J. \& Nemec, M. QSAR for toxicity of saturated and unsaturated halogenated aliphatic compounds. Chemosphere, 36(6), pp. 1345-1365, 1998.

[5] International Programme on Chemical Safety (IPCS). OECD screening information data set (SIDS). 3,4-Dichlorobut-1-ene. UNEP Publications. www.inchem.org/documents/sids/sids/760236.pdf

[6] International Programme on Chemical Safety (IPCS). OECD screening information data set (SIDS). 2,3,4-Trichloro-1-butene. UNEP Publications. www.inchem.org/documents/sids/sids/24031507.pdf

[7] Clary, J.J. Toxicity of chloroprene, 1,3-dichlorobutene-2, and 1 ,4dichlorobutene-2. Environmental Health Perspectives, 21, pp. 269-274, 1977.

[8] European Commission, European Chemicals Bureau. IUCLID dataset, 2,3dichlorobuta-1,3-diene. http://ecb.jrc.it/documents/ExistingChemicals/iuclid/data_sheets/1653196.pdf

[9] Bartsch, H., Malaveille, C., Barbin, A. \& Planche, G. Mutagenic and alkylating metabolites of halo-ethylenes, chlorobutadienes and 
diehlorobutenes produced by rodent or human liver tissues. Archives of Toxicology, 41(4), pp. 249-277, 1979.

[10] Mullin, L.S., Kennedy Jr., G.L. \& Wood, C.K., Nasal tumors in rats following long-term inhalation exposure to 1,4-dichlorobutene-2 (DCB). Drug \& Chemical Toxicology, 23(3), pp. 403-417, 2000.

[11] Feron, V.J., Woutersen, R.A., van Garderen-Hoetner, A. \& Dreef-van der Meulen, H.C., Upper Respiratory Tract Tumors in Cpb:WU (Wistar Random) Rats. Environmental Health Perspectives, 85, pp. 305-315, 1990.

[12] Gillham, R.W. \& O'Hannesin, S.F., Enhanced Degradation of Halogenated Aliphatics by Zero-Valent Iron. Ground Water, 32(6), pp. 958-967, 1994.

[13] Arnold, W.A. \& Roberts, A.L., Pathways and kinetics of chlorinated ethylene and chlorinated acetylene reactions with $\mathrm{Fe}(0)$ particles. Environmental Science \& Technology, 34(9), pp. 1794-1805, 2000.

[14] O'Hannesin, S.F. \& Gillham, R.W., Long term performance of an in situ "iron wall" for remediation of VOCs. Ground Water, 36(1), 164-170, 1998.

[15] Consorti, C.S., Umpierre, A.P., de Souza, R.F., Dupont, J. \& Suarez, P.A.Z., Selective hydrogenation of 1,3-butadiene by transition metal compounds immobilized in 1-butyl-3-methyl imidazolium room temperature ionic liquids. Journal of Brazilian Chemical Society, 14(3), pp. 401-405, 2003.

[16] Schwarzenbach, R.P., Gschwend, P.M. \& Imboden, D.M., Environmental Organic Chemistry, 2nd ed, John Wiley and Sons, Inc., Hoboken, New Jersey, pp. 206-207, 2003.

[17] Orth, W.S. \& Gillham, R.W., Dechlorination of trichloroethene in aqueous solution using $\mathrm{Fe}^{0}$. Environmental Science \& Technology, 30(1), pp. 66-71, 1996.

[18] Agrawal, A., Ferguson, W.J., Gardner, B.O., Christ, J.A., Bandstra, J.Z. \& Tratnyek, P.G., Effects of carbonate species on the kinetics of dechlorination of 1,1,1-trichloroethane by zero-valent iron. Environmental Science \& Technology, 36(20), 4326-4333, 2002.

[19] O'Hannesin, S.F., Przepiora, A. \& Gillham, R.W., Effect of temperature and iron content on iron PRB design. Presented at the $4^{\text {th }}$ Int. Conf. on Remediation of Chlorinated and Recalcitrant Compounds, Monterey, California, May 24-27, 2004.

[20] European Commission, Joint Research Centre, 1,3-Butadiene. European Chemicals Bureau I-21020 Ispra (VA) Italy. Special Publication I.02.110, United Kingdom, 2002. ecb.jrc.it/documents/ExistingChemicals/risk_assessment/summary/butadienesum019.pdf

[21] International Programme on Chemical Safety (IPCS). OECD screening information data set (SIDS). 2-Butene. UNEP Publications. http:/www.inchem.org/documents/sids/sids/107017.pdf 